\title{
Prevalence and factors associated with the performance of prostate cancer screening in the elderly: a population-based study
}

\author{
Alisson Padilha de Lima',2 \\ Ezequiel Vitório Lini' \\ Rodrigo Britto Giacomazzi \\ Marcos Paulo Dellani ${ }^{1}$ \\ Marilene Rodrigues Portella' \\ Marlene Doring'
}

\section{Abstract}

Objective: to identify the prevalence and factors associated with preventive examinations for the screening of prostate cancer in the elderly. Methods: a cross-sectional populationbased study of 181 men aged $\geq 60$ years who were residents of a small city in the state of Rio Grande do Sul, Brazil, was carried out. The dependent variable was considered to be the performance of preventive prostate cancer tests in the past two years and the independent variables were those related to health and sociodemographic characteristics. To test the association between the outcome and the independent variables, gross and multivariable analysis using Poisson regression was performed, estimating the gross and adjusted prevalence ratios, calculating the confidence intervals of $95 \%$. All variables with $p \leq 0.20$ were included in the multiple model. Results: the prevalence of preventive examinations for prostate cancer was $89 \%$. The tests used were the Prostate Specific Antigen (PSA) (85.7\%), followed by tests performed in combination: rectal examination and PSA (9.3\%), rectal examination, ultrasound and PSA (3.1\%), rectal examination and ultrasound $(1.3 \%)$ and ultrasound and PSA (0.6\%). In multivariate analysis, the variables retirement and marital status were the independent factors associated with the carrying out of at least one preventive examination of the prostate. Conclusions: The findings demonstrate that being retired increases the likelihood of carrying out preventive examinations and having a partner, being married or cohabiting increases the likelihood of undergoing tests.

Keywords: Risk Factors. Neoplasms. Health of the Elderly.

\footnotetext{
Universidade de Passo Fundo (UPF), Faculdade de Educação Física e Fisioterapia, Programa de Pósgraduação Stricto Sensu em Envelhecimento Humano. Passo Fundo, RS, Brasil.

2 Associação Educacional Luterana Bom Jesus, Faculdade de Educação Física. Joinville, SC, Brasil.
} 


\section{INTRODUCTION}

Brazil is undergoing a period of epidemiological transition, with profound changes in health and disease patterns interacting with demographic, economic, social, cultural and environmental factors ${ }^{1}$. Currently, Chronic Noncommunicable deaths in Brazil².

According to research conducted by the National Cancer Institute (INCA), there were 61,200 new cases of prostate cancer in Brazil in 2016. These figures correspond to an estimated risk of 61.82 new cases per 100,000 men. Without considering non-melanoma skin tumors, prostate cancer is the most common type of cancer among men in all regions of the country, with $95.63 / 100,000$ in the south, $67.59 / 100,000$ in the midwest, $62.36 / 100,000$ in the southeast, $51.84 / 100,000$ in the northeast and $29.50 / 100,000$ in the north ${ }^{3}$.

Prostate cancer is currently the second most common cancer in the world for males, and the fifth most common overall, with an estimated 900,000 new cases diagnosed in 2008, affecting about $14 \%$ of the world's men ${ }^{4}$.

While the etiology of prostate cancer is not fully known, the main risk factors for the development of the disease include the presence of testosterone and age. Screening practices for prostate cancer, especially among Brazilian elderly persons, are still little known ${ }^{5}$.

Rectal examinations, as described in literature, is one of the forms of screening for prostate cancer. It is a low-cost procedure that allows the size, shape and consistency of the prostate to be evaluated, but is often viewed in a prejudiced manner due to being interpreted as an affront to masculinity, which may influence adherence to the exam as a prevention strategy ${ }^{6}$.

Screening exams can be considered as the most important part of the treatment of prostate cancer, as early diagnosis provides an opportunity to offer a more effective treatment method for maintaining the quality of life of men?.

The difficulty in adherence to prevention tests, especially rectal examinations, and elderly subjects

who have never performed preventive and screening examinations, indicates the continuing need for educational health programs relating to prostate cancer and early detection tests, focusing primarily on the elderly.

The aim of the present study was to identify the prevalence and factors associated with the performance of preventive tests for the screening of prostate cancer in the elderly.

\section{METHODS}

A cross-sectional population-based study with elderly residents of the town of Estação in the state of Rio Grande do Sul was performed. Estação is located in the northwest region of the state, 256,17 $\mathrm{km}$ from the state capital of Porto Alegre. At the time of data collection, it had a population of 6,253 inhabitants, of which 992 were 60 years of age or older, representing $15.9 \%$ of the total population.

The Municipal Health Department possesses an outpatient clinic, which provides basic health care for the population. This outpatient unit houses the Family Health Strategy (FHS), which covers $100 \%$ of the micro areas of the region and a small for-profit hospital which has a partnership agreement with the municipal region. The referral city in health services for this region, in cases where infrastructure with greater technology is required, is located $31 \mathrm{~km}$ away. In terms of the provision of care services, $100 \%$ of the municipal region is covered by the FHS.

The municipal region also outsources some specialized laboratory services, procedures and medical consultations, in order to meet the demand of its residents. In addition, it has partnership agreements with other municipal regions which are reference centers for urgent and emergency care. Preventive examinations in men's health are performed by the general practitioner and only when disorders occur is the patient referred to a specialist in the accredited reference municipal region.

For the identification and location of the study population, the Basic Health Information System of the Municipal Health Department for the year 2011 was used. For the calculation of the sample, the population of elderly men $(\mathrm{N}=457)$, 
expected frequency of the outcome of the preventive examination of prostate cancer ( $80 \%$ ), acceptable error of $5 \%$ and confidence level of $95 \%$ were applied, giving a total of 160 individuals. To compensate for possible losses of $10 \%$ (non-eligibility, refusals, among others), an additional number of elderly persons was included as a safety margin, resulting in a total of 176 elderly.

The sample, however, contained 181 elderly men, randomly selected from the records of the ESF. Initially, they were listed by area of residence and gender and then selected by random sampling, maintaining the proportions stipulated by the sample.

The inclusion criteria were: reside for at least six months in the municipal region; possess the cognitive ability to respond to the questionnaire, or have a family member or caregiver present to assist with or provide the answers. Data collection was carried out between February and May 2011, following approval of the project by the Research Ethics Committee in of the Universidade de Passo Fundo. The collection instrument was a questionnaire structured and adapted from the questionnaire of Aging, Health and Welfare Research (SABE) .

A pilot test was performed by the interviewer to see if the instructions were clear when the instrument was applied to the respondents. The interviews were carried out individually at a convenient time and place for the interviewees, mostly in their homes.

The dependent variable was considered to be the carrying out of preventive examinations of prostate cancer in the last two years and the independent variables were those related to health conditions and sociodemographic characteristics. We did not investigate symptoms that may have induced the elderly to seek consultations or prostate exams, nor question the presence of prostatic or urinary diseases.

Descriptive and bivariate analysis of the data was performed. In order to test the association between the outcome and the independent variables, crude and multivariate analyzes were performed using Poisson regression, estimating crude and adjusted prevalence ratios, calculating the respective $95 \%$ confidence intervals. All variables with $p \leq 0.20$ were included in the multiple model.
The research plan was approved by the Research Ethics Committee of the Universidade de Passo Fundo under $N^{\circ}$ 017/2011 and all the participants signed a Free and Informed Consent Form.

\section{RESULTS}

A total of 181 elderly men with a mean age of 70 years $( \pm 7.2)$, ranging from 60 to 94 years old, participated in the study. Most were white, married or had a partner, could read and write, were retired and received from one to two minimum wages (Table 1).

The prevalence of at least one of the preventive exams for prostate cancer in the period up to two years prior to the interview date was $89 \%$. The most frequent was Prostate Specific Antigen (PSA) (85.7\%), followed by exams performed together: rectal examination and PSA (9.3\%), rectal examination, ultrasound and PSA (3.1\%), rectal examination and ultrasound $(1.3 \%)$ and ultrasound and PSA $(0.6 \%)$.

Of the men who did not undergo prostate health screening, 100\% did not do so because they considered it unnecessary. When questioned about the last time they required health care, $100 \%$ of the elderly reported that the consultation was performed by doctors.

Table 1 shows that the variables housing, marital status, retirement and reading and writing skills were associated with the performance of preventive exams for prostate cancer $(p<0.05)$. Prostrate cancer exams were more frequent among elderly retirees, married men, and those who could read and write. Retired elderly men performed twice as many preventive prostate exams as non-retirees. Being married or having a partner was a protective factor $(\mathrm{PR}=0.22)$ for the examination.

In table 2 , the variables self-evaluation of health, presence of chronic pain, smoking and seeking health care, were not statistically associated with the outcome $(p<0.05)$.

In the multivariate analysis, the variables retirement and marital status were independent factors associated with at least one prostate screening exam (Table 3). 
Table 1. Gross prevalence ratios of performance of at least one prostate exam by sociodemographic variables of elderly men in Estação, Rio Grande do Sul, 2011.

\begin{tabular}{|c|c|c|c|c|}
\hline Variables & $\mathrm{n}$ total & $\begin{array}{l}\text { Prevalence of } \\
\text { exams }(\%)\end{array}$ & $p^{*}$ & Gross PR (CI 95\%) \\
\hline Age range (years) & & & 0.683 & \\
\hline 60 to 69 & 93 & 87.1 & & 1 \\
\hline 70 to 79 & 70 & 91.4 & & $0.63(0.22-1.78)$ \\
\hline 80 or more & 18 & 88.9 & & $0.84(0.17-4.17)$ \\
\hline Area of residence & & & 0.027 & \\
\hline Urban & 119 & 91.6 & & 1 \\
\hline Rural & 29 & 93.1 & & $0.81(0.17-3.93)$ \\
\hline Mixed & 33 & 75.8 & & $3.48(1.22-9.98)$ \\
\hline Marital status & & & 0.004 & \\
\hline Divorced/separated/widowed & 20 & 70 & & 1 \\
\hline Married/common-law-marriage & 161 & 91.3 & & $0.22(0.07-0.69)$ \\
\hline Retired & & & $<0.001$ & \\
\hline Yes & 172 & 91.3 & & 1 \\
\hline No & 9 & 44.4 & & $0.08(0.02-0.34)$ \\
\hline Value of pension (minimum salary) & & & 0.385 & \\
\hline Up to 1 & 61 & 90.2 & & 1 \\
\hline From 1 to 2 & 76 & 89.5 & & $1.08(0.35-3.31)$ \\
\hline$>3$ & 35 & 97.1 & & $0.27(0.03-2.41)$ \\
\hline Can read/write & & & 0.018 & \\
\hline Yes & 162 & 90.7 & & 1 \\
\hline No & 18 & 72.2 & & $3.77(1.15-12.29)$ \\
\hline
\end{tabular}

* $p$ value obtained from Wald Poisson Regression test; $\mathrm{PR}=$ Prevalence ratio; $\mathrm{CI}=$ Confidence interval.

Table 2. Gross prevalence ratios of performance of at least one prostate exam by health-related variables of elderly persons in Estação, Rio Grande do Sul, 2011.

\begin{tabular}{|c|c|c|c|c|}
\hline Variables & $\mathrm{n}$ total & $\begin{array}{l}\text { Prevalence of } \\
\text { exams }(\%)\end{array}$ & $p^{*}$ & Gross PR (CI 95\%) \\
\hline Self assessment of health & & & 0.242 & \\
\hline Very good/good & 120 & 90.8 & & 1 \\
\hline Fair/poor/very poor & 60 & 85 & & $1.75(0.68-4.51)$ \\
\hline Chronic pain & & & 0.939 & \\
\hline Yes & 80 & 88.8 & & 1 \\
\hline No & 99 & 88.9 & & $0.98(0.39-2.52)$ \\
\hline Smoking & & & 0.217 & \\
\hline Smoker & 28 & 82.1 & & 1 \\
\hline Ex-smoker & 58 & 86.2 & & $0.74(0.21-2.52)$ \\
\hline Never smoked & 95 & 92.6 & & $0.36(0.11-1.28)$ \\
\hline Sought health care or assistance & & & 0.311 & \\
\hline Private appointment & 125 & 91.2 & & 1 \\
\hline Public health clinic & 55 & 83.6 & & $2.03(0.78-5.26)$ \\
\hline
\end{tabular}

$* p$ value obtained by Wald's Poisson Regression test; PR= Prevalence ratio; $\mathrm{CI}=$ Confidence interval. 
Table 3. Multiple Poisson regression model for at least one prostrate exam of elderly men in Estação, Rio Grande do Sul, 2011.

\begin{tabular}{ll}
\hline Variables & Adjusted prevalence ratio* (CI 95\%) \\
\hline Retired & $0.08(0.02-0.34)$ \\
Married status & $0.23(0.07-0.75)$ \\
\hline
\end{tabular}

*Adjusted by all variables with significant $p$ value in model; $\mathrm{CI}=$ Confidence interval.

\section{DISCUSSION}

The results obtained show that the elderly men performed some kind of preventive exam for prostate cancer (PC). The most frequent were the PSA and rectal examination + PSA, with the highest probability found in the variables retired and marital status.

These data agree with the study by Restrepo et al. ${ }^{10}$ which evaluated the incidence of mortality among Colombian men aged 16 to 80 years from PC between 1962 and 2011. This study found that the increase in PC coincided with the implementation of the PSA test, or in other words, since this exam was incorporated in the public health system, the level of mortality from PC in the country has decreased, and the period of survival with the disease has increased to five years, being strongly associated with age, period of diagnosis and socioeconomic status.

Preventive exams for PC are of fundamental importance for the diagnosis and early prophylaxis of possible health problems for the elderly. In a review study, Virgine et al. ${ }^{11}$ evaluated several updated recommendations for the treatment and follow-up of different types of cancer in adults, including PC. It was stated that the best form of prevention is routine check-up examinations, which should be carried out constantly.

Despite the high prevalence of performing preventive exams for PC identified in the present study, the study by Belinelo et al. ${ }^{12}$ found different results when analyzing 21 men aged from 51 to 77 years, where the influence of the social imaginary on PC and on the stigma of screening can make men who undergo such exams feel uncomfortable, inhibited, afraid or ashamed.
These findings on feelings of inhibition regarding preventive tests for $\mathrm{PC}$ were also found in the study by Souza et al. ${ }^{13}$ who interviewed 77 men aged 18 to 59 years, only two of whom underwent such preventive exams, data which confirms that the present study identified a high prevalence of PC exams.

Retired men were more likely to carry out preventive exams in the present study. These data are significant as such exams can represent a primary factor in the prevention and treatment of this pathology. Such findings are corroborated by a study by Paz et al. ${ }^{14}$ which found in a study of 155 men with a mean age of 69 years that the highest rates of $\mathrm{PC}$ were found among farmers and retirees.

Several factors considered as risks can influence the diagnosis of PC, and the prevalence of this condition was high among retired men in the present study. In a case-control study conducted with nonretired Iranian men aged 50-75 years, Pouresmaeili et al. ${ }^{4}$ found different results, where the risk factors most associated with PC were the location where the individual lived, the location of their work, smoking and drugs consumed.

When marital status was analyzed, the present study found the highest prevalence of exams was among married elderly persons. A study by Neves et al. ${ }^{15}$ found that the majority of 19 men aged over 51 years evaluated in a study in the city of Pelotas (Rio Grande do Sul) were married. This condition can influence the relationship between a couple, the family context and even the patient's social relations, due to the seriousness of the pathology ${ }^{16}$.

Another study that corroborated the present study in relation to marital situation was carried out by Santiago et al. ${ }^{5}$, who analyzed 2,825 men, with a mean age of 70 years, in Juiz de Fora (Minas Gerais), 
and found that the majority of patients were married, and that many adhered to the practice of screening. This emphasizes the importance of implementing this treatment process in the public health system in a qualified manner and on an appropriate scale.

Family support can be one of the factors that contribute to the fact that married patients with PC undergo preventive examinations more frequently, because they are aware of the importance of tackling this difficult experience, which is intensified by the stigma of frequent association with death, generating fear and insecurity ${ }^{17}$.

The present study presents limitations due to its cross-sectional design. The regional context prevents possible generalizations for the overall population of Brazil, as it applies to a small municipal region. In terms of gerontological care, the results can assist multi-professional health teams, as they offer pertinent elements for the definition of strategies to increase the support offered to men's health.

\section{REFERENCES}

1. Szwarcwald CL, Malta DC, Pereira CA, Vieira ML, Conde WL, Souza Junior PR, et al. Pesquisa Nacional de Saúde no Brasil: concepção e metodologia de aplicação. Ciênc Saúde Coletiva. 2014;19(2):333-42.

2. Instituto Brasileiro de Geografia e Estatística. Pesquisa nacional de saúde 2013. Percepção do estado de saúde, estilos de vida e doenças crônicas. Brasil, Grandes Regiões e Unidades da Federação. Rio de Janeiro: IBGE; 2014.

3. Instituto Nacional do Câncer. Estimativa 2016: incidência de câncer no Brasil. Instituto Nacional de Câncer José Alencar Gomes da Silva. Rio de Janeiro: INCA; 2015.

4. Pouresmaeili F, Hosseini SJ, Farzaneh F, Karimpour A, Azargashb E, Yaghoobi M, et al. Evaluation of environmental risk factors for prostate cancer in a population of Iranian patients. Asian Pac J Cancer Prev. 2014;15(24):10603-5.

5. 5. Santiago LM, Luz LL, Silva JF, Mattos IE. Prevalência e fatores associados à realização de exames de rastreamento para câncer de próstata em idosos de Juiz de Fora, MG, Brasil. Ciênc Saúde Coletiva. 2013;18(12):3535-42.

\section{CONCLUSION}

We can conclude that being retired increases the likelihood of undergoing preventive exams, as is having a partner, either through marriage or common-law marriage, in many cases due to the family support and awareness of the importance of the prevention and treatment of this pathology that this provides, which may prevent further harm to the health of the patient.

The study identified a high prevalence rate of at least one prostate cancer screening test among the elderly men, although literature includes few studies that explain the relationship between preventive tests and marital status.

It is therefore of fundamental importance that other studies are carried out, with different designs and which contemplate different contexts, so that a greater understanding of the associated factors and possible health care of elderly men can be obtained.
6. Gomes R, Nascimento EF, Rebello LE, Araújo FC. As arranhaduras da masculinidade: uma discussão sobre o toque retal como medida de prevenção do câncer prostático. Ciênc Saúde Coletiva. 2008;13(6):1975-84.

7. Paiva EP, Motta MC, Griep RH. Knowledge, attitudes and practices regarding the detection of prostate cancer. Acta Paul Enferm. 2010;23(1):88-93.

8. Nascimento EP, Florindo AA, Chubaci RY. Exame de detecção precoce do câncer de próstata na terceira idade: conhecendo os motivos que levam ou não a sua realização. Rev Baiana Saúde Pública. 2010;34(1):7-18.

9. Lebrão ML, Laurenti R. Saúde, bem-estar e envelhecimento: o estudo SABE no Município de São Paulo. Rev Bras Epidemiol. 2005;8(2):127-41.

10. Restrepo JA, Bravo LE, García-Perdomo HA, García LS, Collazos P, Carbonell J. Incidencia, mortalidad y supervivencia al cáncer de próstata en Cali, Colombia, 1962-2011. Salud Pública Mex. 2014;56(5):440-7.

11. Virgine V, Meindl-Fridez C, Battegay E, Zimmerli LU. Check-up examination: recommendations in adults. Swiss Med Wkly. 2015;30(145):1-11. 
12. Belinelo RG, Almeida SM, Oliveira PP, Onofre PS, Viegas SM, Rodrigues AB. Exames de rastreamento para o câncer de próstata: vivência de homens. Esc Anna Nery Rev Enferm. 2014;18(4):697-704.

13. Souza AF, Silva CS, Alves EC, Pinto IS, Oliveira LS, Souza e Souza LP, et al. Analysis of risk factors related to men's health. Rev Norte Min Enferm. 2014;3(2):6-20.

14. Paz MF, Monte BS, Rego Neto JJ, Tapety FI, Sousa $\mathrm{CM}$, Cavalcante AA. Correlations between risk factors for prostate cancer: na epidemological analysis. Rev Pesqui Cuid Fundam. 2013;5(6):187-99.
15. Neves JL, Schwartz E, Zillmer JG, Lima LM, Feijó AM, Santos BP. Prostate cancer: characterization of users of a service of oncology. J Nurs UFPE on line. 2013;7(11):6360-7.

16. Molina MA, Marconi SS. Mudanças nos relacionamentos com os amigos, cônjuge e família após o diagnóstico de câncer na mulher. Rev Bras Enferm. 2006;59(4):514-20.

17. Rodrigues JS, Ferreira NM, Caliri MH. Characterization of social support perceived for Family to adult patient with cancer. Medicina (Ribeirão Preto) 2013;46(3):288-95.

Received: April 28, 2017

Reviewed: September 12, 2017

Accepted: December 15, 2017 